Western University

Scholarship@Western

Physical Therapy Publications

Physical Therapy School

7-18-2019

Self-Care Trajectories and Reference Percentiles for Children with Cerebral Palsy.

Robert J Palisano

Lisa A Chiarello

Lisa Avery

Steven Hanna

On Track Study Team

Follow this and additional works at: https://ir.lib.uwo.ca/ptpub

Part of the Physical Therapy Commons

Citation of this paper:

Palisano, Robert J; Chiarello, Lisa A; Avery, Lisa; Hanna, Steven; and On Track Study Team, "Self-Care Trajectories and Reference Percentiles for Children with Cerebral Palsy." (2019). Physical Therapy Publications. 47.

https://ir.lib.uwo.ca/ptpub/47 


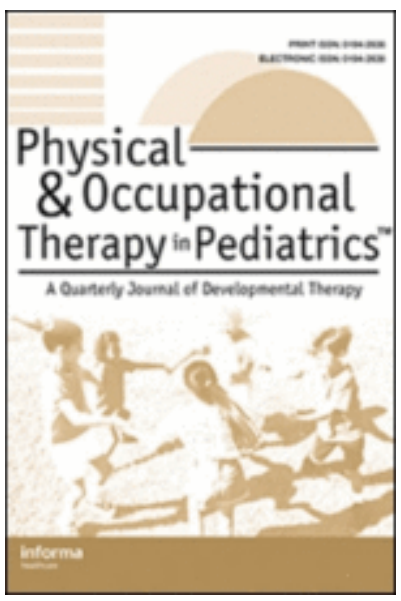

\section{Self-Care Trajectories and Reference Percentiles for Children with Cerebral Palsy}

\begin{tabular}{|r|l|}
\hline Journal: & Physical \& Occupational Therapy In Pediatrics \\
\hline Manuscript ID & WPOP-2018-0184.R1 \\
\hline Manuscript Type: & Original Research \\
\hline Keywords: & $\begin{array}{l}\text { cerebral palsy < Populations, self-care, longitudinal trajectories, } \\
\text { reference percentiles, Child Engagement in Daily Life Measure }\end{array}$ \\
\hline \multicolumn{2}{|l}{} \\
\hline
\end{tabular}

\section{SCHOLARONE" Manuscripts}




\title{
Self-Care Trajectories and Reference Percentiles for Children with Cerebral Palsy
}

\begin{abstract}
.
Aims: To create longitudinal trajectories and reference percentiles for performance in self-care of children with cerebral palsy (CP). Methods: Participants were 708 children with CP, 18 months through 11-years of age and their parents residing in 10 regions across Canada and the United States. Gross Motor Function Classification System (GMFCS) levels were determined by consensus between parents and therapists. Parents' completed the Performance in Self-Care domain of the Child Engagement in Daily Life Measure two to five times at 6-month intervals. Nonlinear mixed-effects models were used to create longitudinal trajectories. Quantile regression was used to construct cross-sectional reference percentiles. Results: The trajectories for children in level I, II, and III are characterized by an average maximum score between 79.6 (level I) and 62.8 (level III) and an average attainment of 90\% of the maximum score between 7 and 9 years of age. The trajectories for children in level IV and V show minimal change over time. Extreme variation in performance among children of the same age and GMFCS level complicate interpretation of percentile change of individual children. Conclusion: The findings are useful for monitoring self-care of children with $\mathrm{CP}$ and evaluating change for children in GMFCS levels I-III.
\end{abstract}

KEYWORDS: Cerebral palsy, self-care, longitudinal trajectories, reference percentiles, Child Engagement in Daily Life Measure 
Measures normed for children with cerebral palsy enable families and professionals to monitor development based on expectations for children of the same age and functional level. Cerebral palsy (CP) refers to a group of neurological disorders affecting the development of posture and movement that are often accompanied by disturbances of sensation, cognition, communication, perception, and behavior (Rosenbaum et al., 2007). Children with CP demonstrate considerable variation in development as evidenced by the gross motor function (Palisano et al. 1997), manual ability (Eliasson et al., 2006), and communication function (Hidecker et al., 2011) classification systems. Each system has fivelevels that represent differences in development thought to be meaningful in daily life.

The 66-item Gross Motor Function Measure (GMFM-66) is a condition specific, interval-level measure validated to evaluate change over time in children with CP (Russell et al., 2013). Gross motor function curves for each of the five levels of the Gross Motor Function Classification System (GMFCS; Palisano et al., 1997) were developed using the GMFM-66 (Hanna et al., 2009; Rosenbaum et al., 2002). Development of gross motor function of children with $\mathrm{CP}$ is nonlinear and potential for change varies by gross motor function classification system level (Hanna et al., 2009; Rosenbaum et al., 2002). Cross-sectional reference percentiles also were developed for the GMFM-66 (Hanna et al., 2008). Reference percentiles provide interpretation of GMFM-66 scores of individual children with $\mathrm{CP}$ based on age and GMFCS level.

Performance in self-care is another area where longitudinal trajectories and reference percentiles for children with $\mathrm{CP}$ would facilitate monitoring performance over time and decision making. Parents of children with $\mathrm{CP}$ identified self-care as their most frequent priority for activity and participation (Chiarello et al., 2010). Similarly, adolescents with CP, 
parents, and health care providers indicated that self-care is an important intervention outcome (Vargus-Adams \& Martin, 2009). Change in self-care of children with CP using the SelfCare domain of the Pediatric Evaluation of Disability Inventory (Haley et al., 1992) was analyzed for 100 children 1-4 years of age with CP by Ketelaar et al. (2014) and 116 children 5-9 years of age with CP by Smits et al. (2010). For children 1-4 years of age, the average developmental trajectory differed by GMFCS level with large individual variation (Ketelaar et al., 2014). For children 5-9 years of age, change in self-care over two years was best predicted by GMFCS level and intellectual ability (Smits et al., 2010).

The Child Engagement in Daily Life Measure (Chiarello et al., 2014) was developed for the Move \& Play (Movement and Participation in Life Activities of Young Children) study to provide a standardized measure that is relatively short and, therefore, feasible to include as part of a comprehensive assessment of children with CP 5 years of age and younger. The measure was designed to be acceptable to parents, easy to score, and a complement to other measures such as the GMFM-66 (Bartlett et al., 2010; Chiarello et al., 2011). The Child Engagement in Daily Life Measure includes two domains: Participation in Family and Recreational Activities (11 items) and Performance in Self-Care (7 items). In comparison, the Self-Care domain of the Pediatric Evaluation of Disability Inventory (Haley et al., 1992) has 74 items. The Child Engagement in Daily Life Measure was validated on a convenience sample of 429 parents of children with $\mathrm{CP}, 18$ to 60 months, and 110 parents of children with typical development of the same ages. The Rasch model of item response analysis (Wright \& Masters, 1982) was used to create an interval-level measure. Performance in self-care varied by children's age and GMFCS level, providing evidence of construct (known groups) validity. Internal consistency (Cronbach alpha $=.90)$ and test-retest 
reliability $\left(\operatorname{ICC}_{(2,1)}=0.96 ; 95^{\text {th }} \mathrm{CI} 0.91-0.98\right)$ are high (Chiarello et al., 2014). The mean change in self-care scaled scores over a 12 -month period was significant and of similar magnitude for children whose gross motor function was classified as level I ( 8.3 points, $p<.001)$ and children whose gross motor function was classified as level II or III (8.0 points, $p<.001$ ). The mean change was not significant for children classified as level IV or V (1.6 points, $p=$ .11) (Palisano et al., 2014). Limitations of the Self-Care domain include the small number of items, only one item of intermediate difficulty, and the concern that items might not adequately measure abilities of children with CP, 6 years of age and older. To address these limitations, the Performance in Self-care domain was revised for the On Track Study (Monitoring Development of Children with Cerebral Palsy and Gross Motor Delay; McCoy et al., 2018). Eleven items were added for a total of 18 self-care items, the upper age was extended to 12 years, and the Rasch model of item response analysis (Wright \& Masters, 1982) was used to create an interval-level measure Performance in Self-Care (Version 2) is described in Table 1 and the methods.

[Insert Table 1]

The aims of this study were to create longitudinal trajectories and reference percentiles for performance in self-care of children with $\mathrm{CP}$, ages 3 to 12 years of age. Longitudinal trajectories estimate average change over time, and the extent of variation among children in the pattern of change. Reference percentiles provide information on the distribution of scores at a given age. Change in reference percentile provides evidence of whether individual children are progressing 'as expected', 'better than expected', or 'less than expected' compared with children of the same age and GMFCS level. Longitudinal trajectories and reference percentiles have application for monitoring performance over time, future planning, goal setting, and decisions on services and interventions. 


\section{METHODS}

This study was part of the multisite, prospective cohort On Track Study (McCoy et al., 2018). The aims of the On Track Study were to develop longitudinal trajectories and reference percentiles for: a) health conditions associated with $\mathrm{CP}, \mathrm{b}$ ) selected body functions and structures, c) performance in self-care, and d) participation in family and recreation activities. The On Track Study was approved by the Institutional Review Board (IRB) at each participating institution and recruitment sites with an IRB. Parents or guardians provided informed written consent and children, as appropriate and in compliance with the specific IRB, provided assent.

\section{Participants}

Participants were a convenience sample of 708 children with CP, 18-months through 11-years of age on entry into the study, whose parents were able to speak and understand English, French or Spanish. Participants were recruited from six provinces across Canada (British Columbia, Saskatchewan, Manitoba, Ontario, Nova Scotia, and Newfoundland) and four states across the United States (Georgia, Oklahoma, Pennsylvania, and Washington) between April 2013 and January 2015. Participating children had either a diagnosis of CP by a physician or demonstrated delay in gross motor development in addition to impairments in muscle tone, postural movements, and range of motion. Eligibility was confirmed and reviewed by a physiatrist throughout the study.

Informed consent was provided by 724 families. Subsequently, data on 16 children were excluded. Data from 11 children were excluded because of a diagnosis other than CP, one child died, and four children were lost to follow-up. A sample size of 700 children was determined to be adequate for estimation of percentiles by age and GMFCS level based on calculations for adequacy of the width of the $95 \%$ CI for the $5^{\text {th }}, 50^{\text {th }}$, and $95^{\text {th }}$ percentiles (Crawford $\&$ Garthwaite, 
2008). A sample of 708 is adequate for estimation of mixed-effects longitudinal models. Participant demographic information is presented in Table 2.

\section{[Insert Table 2]}

\section{Measures}

Gross Motor Function Classification System (GMFCS) (Palisano et al., 2008). The GMFCS is a five-level system used to classify gross motor function of children with CP. Classifications are based on the child's usual performance throughout the day at home, school, and in the community. Emphasis is on sitting, transfers, and mobility. Distinctions between levels are based on functional abilities, use of assistive technology, and to a lesser extent quality of movement. Five age bands (before $2^{\text {nd }}$ birthday; between 2 and 4 years, between 4 and 6 years, between 6 and 12 years, and between 12 and 18 years) account for age related differences in gross motor function. Inter-rater reliability and validity have been established (Palisano et al., 1997; Palisano et al., 2008; Palisano et al., 2006; Palisano et al., 2018).

Child Engagement in Daily Life Measure: Performance in Self-Care (Version 2) (Chiarello et al., 2017). Prior to data collection, the Performance in Self-Care domain was revised. Eleven items were added for a total of 18 self-care items. The original 7 items were divided into subcomponents (i.e. dress upper body was divided into two items: dress upper body and undress upper body), new items were added (e.g. brush hair) and the wording of response options was revised. Items are grouped by three types of activities: Feeding and Drinking ( 6 items), Dressing (5 items), and Grooming and Toileting (7 items) (Table 2). Children may use special equipment, walking devices, or wear an orthosis/brace when performing self-care activities. There are five response options for each item: 5 : Does the activity independently most of the time; 4 : Does the activity independently some of the time; 3 : Does part of the activity independently but 
needs help for some of the activity; 2: Does assist but needs help for all of the activity; and 1: Does not do the activity.

Rasch analys is (Wright \& Masters, 1982) of item responses by the 708 study participants were used to create an interval scoring system based on item calibrations. Analysis of the data was conducted using the mixRasch package (Willse, 2015) in the R statistical language ( $\mathrm{R}$ core team, 2016). The partial credit model was used (Wright \& Masters, 1982). Unidimensionality was confirmed by a scree plot and with the first factor in all of one, two and three-factor models explaining over $70 \%$ of the total variance. Response levels for all items ordered as expected. Person calibrations were re-scaled from the logit scale to scaled scores ranging from 0-100. Raw scores for the 18 items are summed and converted to a scaled score (0-100) using a conversion table. The Child Engagement in Daily Life Measure (Version 2) and conversion tables are available at https://www.canchild.ca.

\section{Procedures}

Parents completed two $(n=656)$ to five $(n=424)$ assessments with a physical therapist or occupational therapist in their homes or clinic settings (initial assessment, 6-months, 12-months, 18-months, 24-months). The process for consensus classification by Bartlett et al. (2016) was used. Each child's gross motor function was independently classified by both the assessor and the parent, then discussed to reach consensus. Consensus was reached $97.8 \%$ of the time, and all disagreements were within one level. Guidelines were generated to reconcile disagreements. Fundamentally, we relied on parents' classifications. The GMFCS level of the therapist was used only when the therapist provided compelling comments on the classification form $(2.2 \%)$. Our rationale is that parents know their children the best, see them in multiple settings, and are best able to describe usual performance. 
The Child Engagement in Daily Life Measure was one of several measures completed by parents at each assessment. Parents were asked if they preferred the questions and response options read by the assessor. The assessor was available to address questions and checked completed forms for technical errors. Time to complete the Child Engagement in Daily Life Measure was 10-15 minutes.

\section{Data Analysis}

There were very limited missing data. Details of how missing data were dealt with are described by McCoy et al. (2018).

\section{Longitudinal trajectories}

To create longitudinal trajectories describing the average change in performance of self-care between 3 and 12 years of age, nonlinear mixed-effects models (Pinheiro \& Bates, 2004) were fit for each of the five GMFCS levels. Based on inspection of plots of participants' scaled scores by GMFCS level, asymptotic models were fit allowing for early change followed by a leveling off toward an upper limit of performance. The models have an asymptote or limit parameter (maximum scaled score), a 'time-90' rate parameter (average time taken for children to reach $90 \%$ of their individual maximum scaled score), and, if necessary, an additional offset parameter to improve model fit. Descriptions of the models are provided in the Appendix. Choice of which model to use was based on Akaike's Information Criteria. Model 1 (with an offset) was used for children classified as GMFCS level I, II, or III. Model 2 (no offset) was used for children classified as GMFCS level IV or V. Random effects were fit for each parameter to estimate the variability among children in the true change parameters. Models were fit using the nlme package (Pinhero et al., 2016) in the R statistical language (R core team, 2016). 


\section{Reference Percentiles}

Scaled scores from the first, 12-month, and 24-month assessment sessions were analyzed via quantile regression $(\mathrm{QR})$ to construct cross-sectional reference percentiles. We aimed to estimate the $3 \mathrm{rd}$, 5th, 10th, 25th, 50th, 75th, 90th, 95th, and 97th percentiles. For some GMFCS levels the full range could not be estimated because of floor or ceiling effects. To maximize the sample size, the analysis included up to three assessments from each child using the quantregGrowth package in R (Muggeo et al., 2013). The quantregGrowth package uses linear combinations of multiple bases functions to estimate smooth quantiles across the age continuum and constrains the percentiles to be non-crossing (Muggeo et al., 2013).

We determined the mean change in percentile score based on age and GMFCS level, using the calculated percentile scores for all children with baseline and 12-month assessments. The change in each child's percentile score over this 12-month period ( \pm 3 months) was calculated by subtracting the baseline percentile score from the 12-month percentile score. The distribution of these 12 -month percentile change scores was used to estimate bands that encompass $50 \%$ and $80 \%$ of changes. These bands quantify the change in percentile scores that are typical in children with CP. Following Hanna et al., (2008), we recommend that children whose change in percentile score is within the $80 \%$ interval can usually be described as 'progressing as expected' for their age and GMFCS level.

\section{RESULTS}

\section{Longitudinal trajectories}

The longitudinal trajectories for performance in self-care are presented in Figure 1. The model parameters used to create the trajectories are presented in Table 3. The estimated average 
maximum scaled score (limit parameter) varies from 79.6 (children classified as level I) to 14.5 (children classified as level V). The mean difference in average maximum scaled score between children in each successive GMFCS level is large except for the difference between children classified as level II (67.7) and children classified as level III (62.8). For each trajectory, there is considerable variation in scaled scores among children of the same age. Figure 1 shows a child in Level II who obtained a score of 0 . While we surmised the ratings were reversed (true score of 100), we had no objective basis to exclude the score from analysis. The residual standard deviations reported in Table 3 estimate the average amount of variability in observed scores around a child's true trajectory. Based on these values, variability in self-care scaled scores is greatest among children classified in level V.

For children whose gross motor function is classified as level I, II, or III, estimated average scaled scores increase 13.9 to 17.3 points between 2 and 5 years of age and 9.7 to 12.5 points between 5 and 12 years of age (Table 3). Time-90 estimates in Table 3 show that for children classified as levels I, II, or III, rate of progress toward the maximum scaled score is inversely related to gross motor function level. On average, children classified in level III achieve $90 \%$ of their capacity by 107 months as opposed to 80 months for children classified in Level I.

For children whose gross motor function is classified as level IV or V, estimated average scaled scores increase by 8.3 points (level IV) and 1.6 points (level V) between 2 and 5 years of age. Estimated average scaled scores increase by 1.3 points (level IV) and 0.4 points (level V) between 5 and 12 years of age. For children classified as level IV or V, the time-90 value is less meaningful because the models predict minimal change in average performance in self-care.

[Insert Figure 1 and Table 3] 


\section{Reference Percentiles}

Reference percentiles for performance in self-care are presented in Figure 2. In general, the spread of scores increases with age. Forty-four children classified as level I had scores of 100 (ceiling effect); therefore, reference percentiles could not be calculated above the $75^{\text {th }}$ percentile. Twentysix children classified as level II had scores of 100 ; consequently the $97^{\text {th }}$ percentile could not be estimated. In contrast, many children classified as level IV or V had scores of 0 (floor effect). Reference percentiles could not be calculated below the $10^{\text {th }}$ percentile for children classified in level IV, and below the $50^{\text {th }}$ percentile for children classified as level V.

Mean change in reference percentiles for a 12-month period ( \pm 3 months) along with $50 \%\left(25^{\text {th }}-75^{\text {th }}\right.$ percentile $)$ and $80 \%\left(10^{\text {th }}-90^{\text {th }}\right.$ percentile $)$ intervals are presented in Table 4. Mean change in reference percentile varies from 8.5 (children classified as level I) to 0.7 (children classified as level V). Standard deviations are large (14.1-20.4). Consequently, the percentile change encompassed by the $80 \%$ intervals are large and vary from 35 percentiles (children classified as level V) to 50 percentiles (children classified as level I).

The following describes the interpretation of change in reference percentile based on the $80 \%$ interval. For children classified as level I, the percentile change for the $80 \%$ interval is 50 percentiles, $-13\left(10^{\text {th }}\right.$ percentile $)$ to $+37\left(90^{\text {th }}\right.$ percentile $)$. A change between -13 and +37 percentiles, therefore, suggests progress is 'as expected'. A change greater than 37 percentiles suggests progress is 'better than expected'; while a change less than - 13 percentiles suggests progress is 'less than expected'.

[Insert Figure 2 and Table 4] 


\section{DISCUSSION}

The longitudinal trajectories and reference percentiles for performance in self-care of children with $\mathrm{CP}$ have applications for monitoring performance, future planning, goal setting, and decisions on services and interventions. Although children are grouped by GMFCS level, this does not imply that age and gross motor function are the only determinants of performance in self-care. Higher performance in self-care of children with CP 18 to 60 months of age was associated with higher gross motor function, fewer health conditions, and higher levels of adaptive behavior (Bartlett et al., 2014). Among participants in the On Track study, higher frequency of participation in family and recreational activities was associated with higher gross motor and higher communication function, while more enjoyment of participation was associated with higher communication function (Alghmadi et al., 2017). Manual ability is an essential component of self-care activities; therefore, we anticipate that manual ability is a determinant of performance in self-care of children with CP. In particular, gross motor function of children with hemiplegia is most often classified as level I; however, depending on impairment in motor control of the more involved arm and hand, manual ability might be classified as level II or III further impacting performance in self-care.

Our findings indicate that the Child Engagement in Daily Life Measure: Performance in SelfCare (Version 2) is responsive to change over time in children with CP 3 through 9 years of age classified as level I, II, or III. The exception are children classified as level I or II who perform all activities independently (score of 100). These findings support use as an outcome measure for this subset of children with CP. Time for completion is feasible for use in practice. Additionally, parent report measures engage families in the intervention process.

In contrast, children whose gross motor function is classified as level IV or V have limited independence in self-care and approach their limits of performance in early childhood. We do not 
recommend using the Performance in Self-Care domain as an outcome measure for children whose gross motor function is classified as level IV or V. Our findings are consistent with change in performance in self-care previously reported for young children with cerebral palsy over a 12month period (Palisano et al., 2014).

The estimated average maximum and time-90 scaled scores indicate that although children whose gross motor function is classified as level I, II, or III improve performance in self-care up to approximately 7 to 9 years of age, most do not achieve a scaled score of 100 . Consequently, most children receive assistance for some self-care activities throughout early and middle childhood. Children whose gross motor function is classified as level IV or V have limited independence in self-care and approach their limits of performance in early childhood. The finding that the spread of scores increases with age may reflect that self-care activities are more complex in older children based on their personal preferences and expectations for clothing and grooming and having to perform self-care activities more often at school and in the community.

The large $80 \%$ intervals complicate interpretation of change in reference percentile for selfcare of individual children. The large $80 \%$ intervals reflect the extreme variation in performance among children of the same age and gross motor function level. The increase in the spread of scores with age may reflect that as children get older contextual factors have a greater influence on performance of self-care. An important question, not addressed in our study, is whether children whose percentile change in self-care indicates that progress is 'less than expected' have changes in body functions, structures, or health conditions that necessitate immediate attention. 


\section{Limitations}

This was a sample of convenience. Although there were 708 participants residing in 10 geographical regions of Canada and the United States, data on participant race, ethnicity, and family income indicate the sample may not be representative of the demographics of the population of families and children with CP.

The asymptotic models applied are modifications of the 'stable limit' model used for the gross motor function curves for children with CP (Hanna et al., 2009; Rosenbaum et al., 2002). There were some challenges in fitting models for performance in self-care of children classified in level I, II, or III that necessitated the addition of an offset parameter. The offset parameter makes the stable limit model much more flexible, and ensured a good fit to the data, but there are some disadvantages. Unlike the limit and time-90 parameters, the offset has no meaningful clinical interpretation. The inclusion of the offset also means that the model predictions do not apply reliably to children below age 3 . For consistency, we also applied the stable limit asymptotic models to create trajectories for children classified in level IV or V (without an offset), where it is evident from Figure 1 that these models largely reduce to a flat line in the absence of systematic average change with age. Because we have very little data on children younger than 3 years, for most children classified as levels IV or V, any change in self-care happened before we could observe it. The time-90 estimates for levels IV and V, therefore, are likely not reliable.

\section{Implications for Practice}

We recommend that therapists share with families the purpose of the Performance in Self-Care domain and explain that scores are one source of information for decision making. Our impression, informed by perspectives of seven parents of children with $\mathrm{CP}$ who were part of our research team 
(Diller et al., 2017a; Diller et al., 2017b) and a survey of parents who were study participants, is that families are most interested in information that is useful in understanding their children's current abilities and supporting their children's activity and participation. Some families are not interested in how their children's performance compares with the performance of other children, while other families prefer detailed explanations. Based on our experiences, families also are interested in anticipatory guidance and future planning. The longitudinal trajectories are a source of evidence; however, sensitivity is important as the trajectories estimate average not individual performance. During the On Track Study, a few parents of children classified in level V shared with therapist assessors that it was emotionally difficult to complete measures when their children were unable to perform most items.

The Ease ofCaregiving forChildren(Wardetal., 2014) is the more appropriate standardized measure for children whose gross motor function is classified as level IV or V. The Ease of Caregiving for Children is a 12-item parent report measure of how difficult it is to safely help the child with activities of daily living including positioning, moving, eating, drinking, dressing, bathing, toileting, and playing. The measure takes 10 to 15 minutes to complete. Change in ease of caregiving reported by parents of young children with CP whose gross motor function was classified as level IV or V was less than the criterion for a small effect, indicating further research is needed to determine responsiveness to change overtime (Palisano et al., 2014).

\section{Case Scenario}

A scenario of a study participant was selected to illustrate interpretation of the longitudinal trajectories and reference percentiles. Naiwen (pseudonym) is a girl with CP. Her gross motor function is classified as level II, manual ability as level II, and communication function as 
level I. When Naiwen was 10 years-old, her mother completed the Performance in Self-Care (Version 2) domain. Naiwen's scaled score was 71 and her percentile 65 (Figures 1 and 2, indicated by first asterisk in graphs for level II). The percentile indicates that her score was higher than the scores of $65 \%$ of children in level II who are 10 years of age. One year later (11 years-old), Naiwen's mother completed the Performance in Self-Care domain a second time. Naiwen's scaled score was 62 and her percentile 35 (Figures 1 and 2, indicated by second asterisk in graphs for level II). The percentile indicates that her score was higher than the scores of $35 \%$ of children in level II who are 11 years of age. Naiwen's change in reference percentile between 10 and 11 years of age was - 30, suggesting progress was 'less than expected' (Table 4).

Identification of self-care activities where performance changed is important for decision making. Compared to the previous year, mother's ratings changed from 5 (Does the activity independently most of the time) to 4 (Does the activity independently some of the time) for the activities (items): undress upper body, dress upper body, undress lower body, dress lower body, wash and dry hands, wash body, and brush teeth. Mother's ratings changed from 5 to 3 (Does part of the activity independently but needs help for some of the activity) for the following activities (items): drying body and wiping nose.

In reviewing scores of other measures completed as part of a comprehensive assessment during the On Track Study, Naiwen's percentile change on the Early Clinical Assessment of Balance (McCoy et al., 2012) and the Child Health Conditions Questionnaire (Bartlett et al., 2018) indicate progress was 'less than expected'. Noteworthy, on the Child Health Conditions Questionnaire, mother reported pain was affecting Naiwen's daily activities a 'moderate extent' compared to the previous year when she reported a 'small extent'. Mother also reported that seeing (vision) was 
affecting Naiwen's daily activities a 'very great extent' compared to a 'great extent' reported the previous year. A consideration is a vision examination by an optometrist. Had we been following Naiwen for therapy services, we would share the collective findings in formats preferred by Naiwen and her family. Then we would encourage Neiwen and her family to share their thoughts on the change in performance in self-care and potential actions.

\section{CONCLUSIONS}

Longitudinal trajectories and reference percentiles for performance in self-care of children with CP have implications for monitoring performance and for children 3 to 9 years of age whose gross motor function is classified as level I, II, or III, evaluating change over time. The Child Engagement in Daily Life Measure: Performance in Self-Care (Version 2) is feasible for use in practice and engages families in the intervention process. We recommend that family preferences guide how findings are shared and that findings are one source of information for decision making.

Conflicts of Interest: The authors report no conflicts of interest. 


\section{REFERENCES}

Alghmadi, M.S., Chiarello, L.A., Palisano, R.J., McCoy, S.W. (2017). Understanding participation of children with cerebral palsy in family and recreational activities. Research in Developmental Disabilities, 69, 96-104.

Barlett, D.J., Chiarello, L.A., Westcott McCoy, S., Palisano, R.J., Rosenbaum, P.R., Jeffries, L., \& LaForme Fiss, A. (2010). The Move \& PLAY Study: An example of comprehensive rehabilitation outcomes research, Physical Therapy, 90, 1660-1672.

Bartlett, D.J., Chiarello, L.A., Palisano, R.J., Westcott McCoy, S., Jeffries, L., Laforme Fiss, A., \& Wilk, P. (2014). Determinants of self-care participation of young children with cerebral palsy. Developmental Neurorehabilitation, 17(6), 403-413.

Bartlett, D.J., Galuppi, B., Palisano, R.J., \& Westcott McCoy S. (2016). Consensus classifications of gross motor, manual ability, and communication function classification systems between therapists and parents of children with cerebral palsy. Letter to the editor. Developmental Medicine and Child Neurology, 58(1), 98-99.

Bartlett, D.J., Gorter, J.W., Jeffries, L.M., Avery, L., Hanna, S.E., \& On Track Study Team (2018). Longitudinal trajectories and reference centiles for the impact of health conditions on daily activities of children with cerebral palsy. Developmental Medicine and Child Neurology, October 23 [Epub ahead of print].

Diller, L., Drew, P., Gilbert, M., Ford, N., hjorngaard, t., Rayfield, K., \& Taylor, B. (2017). Bringing the family's voice to research: parents as members of the research team (part one), www.e-Parent.com, October 27. 
Diller, L., Drew, P., Gilbert, M., Ford, N., hjorngaard, t., Rayfield, K., \& Taylor, B. (2017). Bringing the family's voice to research: how families contribute to research (part two). www.e-Parent.com, December 16.

Chiarello, L., Palisano, R., Maggs, J., Orlin, M., Almasri, N., Kang, L.J., \& Chang, H. (2010). Family priorities for activity and participation of children and youth with cerebral palsy. Physical Therapy, 90, 1254-1264.

Chiarello, L.A., Palisano, R.J., Bartlett, D.J., \& McCoy, S.W. (2011). A multivariate model of determinants of change in gross-motor abilities and engagement in self-care and play of young children with cerebral palsy. Physical \& Occupational Therapy in Pediatrics, 31(2):150-168.

Chiarello, L.A., Palisano, R.J., Westcott McCoy, S., Bartlett, D., Wood, A., Kang, L.J., Chang, H.J., \& Avery, L. (2014). Child Engagement in Daily Life: A measure of participation for young children with cerebral palsy. Disability and Rehabilitation, 36, 1804-1816.

Chiarello, L.A., Palisano, R.J., Westcott McCoy, S, \& Bartlett, D.J. (2017). Child Engagement in Daily Life: Participation in Self-Care (Version 2). https://www.canchild.ca

Crawford, J.R., \& Garthwaite, P.H. (2008). On the "optimal" size for normative samples in neuropsychology: Capturing the uncertainty when normative data are used to quantify the standing of a neuropsychological test score. Child Neuropsychology, 14, 99-117.

Eliasson, A.C., Krumlinde-Sundholm, L., Rösblad, B., Beckung, E., Arner, M., Öhrvall, A.M., \& Rosenbaum P. (2006). The Manual Ability Classification System (MACS) for children with cerebral palsy: scale development and evidence of validity and reliability. Developmental Medicine and Child Neurology, 48, 549-554. 
Haley, S.M., Coster, W.J., Ludlow, L.H., Haltiwanger, J., \& Andrellos P. (1992). Pediatric Evaluation of Disability Inventory (PEDI). Boston: New England Medical Center Hospitals.

Hanna, S.E., Rosenbaum, P.L., Bartlett, D.J., Palisano, R.J., Walter, S.D., Avery, L., \& Russell, D.J. (2009). Stability and decline in gross motor function among children and youth with cerebral palsy aged 2 to 21 years. Developmental Medicine and Child Neurology, 51, 295302.

Hanna, S.E., Bartlett, D.J., Rivard, L.M., \& Russell, D.J. (2008). Reference curves for the Gross Motor Function Measure: percentiles for clinical description and tracking over time among children with cerebral palsy. Physical Therapy, 88, 596 - 607.

Hidecker, M.J.C., Paneth, N., Rosenbaum, P.L., Kent, R.D., Lillie, J., Eulenberg, J.B., Chester, K., Johnson, B., Michalsen, L., Evatt, M., \& Taylor, K. (2011). Developing and validating the Communication Function Classification System (CFCS) for individuals with cerebral palsy. Developmental Medicine and Child Neurology, 53, 704-710.

Ketelaar, M., Gorter, J.W., Westers, P., Hanna, S., \& Verhoef, M. (2014). Developmental trajectories of mobility and self-care capabilities in young children with cerebral palsy. Journal of Pediatrics, 164, 769-774.e2.

McCoy, S.W., Yocum, A., Bartlett, D.J., Mendoza, J., Jeffries, L., Chiarello, L., \& Palisano, R.J. (2012). Development of the Early Activity Scale for Endurance for children with cerebral palsy. Pediatric Physical Therapy, 24(3), 232-240.

McCoy, S.W., Bartlett, D., Smersh, M., Galuppi, B., Hanna, S., \& On Track Study Team ( 2018 ). Monitoring development of children with cerebral palsy: 
The On Track Study. Protocol of a longitudinal study of development and services. Available at: https://www.canchild.ca/en/resources/294-monitoringdevelopment-of-children-with-cerebral-palsy-the-on-track-study-protocol-of-alongitudinal-study-of-development-and-services. Accessed October 29, 2018.

Muggeo,V., Sciandra, M., Tomasello, A., \& Calvo, S. (2013). Estimating growth charts via nonparametric quantile regression: a practical framework with application in ecology. Environmental and Ecological Statistics, 20, 519-531.

Palisano, R.J., Rosenbaum, P., Walter, S., Russell, D., Wood, E., \& Galuppi, B. (1997). Development and validation of a gross motor function classification system for children with cerebral palsy. Developmental Medicine and Child Neurology, 39, 214-223.

Palisano, R.J., Cameron, D., Rosenbaum, P.L., Walter, S.D., \& Russell, D. (2006). Stability of the Gross Motor Function Classification System, Developmental Medicine and Child Neurology, 48, 424-428.

Palisano, R.J., Rosenbaum, P., Bartlett, D., \& Livingston, M.H. (2008). Content validity of the expanded and revised Gross Motor Function Classification System. Developmental Medicine and Child Neurology, 50, 744-750.

Palisano, R.J., Chiarello, L.A., Westcott McCoy, S., Bartlett, D., \& An, M. (2015) Use of the Child Engagement in Daily Life and Ease of Caregiving for Children to evaluate change in young children with cerebral palsy. Physical \& Occupational Therapy in Pediatrics, 35(3), $280-295$. 
Palisano, R.J., Avery, L., Gorter, J.W., Galuppi, B., \& McCoy, S.W. (2018). Stability of the Gross Motor Function, Manual Ability, and Communication Function Classification Systems. Developmental Medicine and Child Neurology, 60(10), 1026-1032.

Pinheiro, B., \& Bates, D. (2004). Mixed-Effects models in S and S-PLus, New York: Springer.

Pinheiro, J., Bates, D., DebRoy, S., \& Sarkar, D. (2016). nlme: Linear and Nonlinear Mixed Effects Models. Retrieved from http://CRAN.R-project.org/package=nlme

R Development Core Team (2016). R: A language and environment for statistical computing. R Foundation for Statistical Computing, Vienna, Austria. http://www.R-project.org.

Rosenbaum, P.L., Walter, S.D., Hanna, S.E., Palisano, R.J., Russell, D.J., \& Raina, P. (2002). Prognosis for gross motor function in cerebral palsy: creation of motor development curves. Journal of the American Medical Association, 288(11), 1357-1363.

Rosenbaum, P., Paneth, N., Leviton, A., Goldstein, M., \& Bax, M. (2007). A report: the definition and classification of cerebral palsy April 2006. Developmental Medicine and Child Neurology, Supplement, 109, 8-14.

Russell, D.J. Rosenbaum, P.L., Wright, M., \& Avery, L.M. (2013). Gross Motor Function Measure (GMFM-66 and GMFM-88) users' manual (2nd Edition). Clinics in Developmental Medicine, Mac Keith Press: London.

Smits, D.W., Ketelaar, M., Gorter, J.W., Van Schie, P., Dallmeijer, A., Jongmans, M., \& Lindeman E. (2011). Development of daily activities in school-age children with cerebral palsy. Research in Developmental Disabilities, 32, 222-234.

Ward, K.D., Chiarello, L.A., Bartlett, D.J., Palisano, R.J., Westcott McCoy, S., \& Avery, L. (2014). Ease of Caregiving for Children: A measure of parent perceptions of the 
physical demands of caregiving for young children with cerebral palsy. Research in Developmental Disabilities, 35, 3403-3415.

Willse, J. T. (2015). Mixture Rasch Models with JMLE. Retrieved from CRAN: https://cran.rproject.org/web/packages/mixRasch/mixRasch.pdf

Wright, B.D., \& Masters G.N. (1982). Rating scale analysis: Rasch Measurement. Chicago (IL): MESA Press.

Vargus-Adams, J.N., \& Martin, L.K. (2009). Measuring what matters in CP: a breadth of important domains and outcome measures. Archives of Physical Medicine and Rehabilitation, 90, 2089-2095. 


\section{TABLE 1. Child Engagement in Daily Life: Participation in Self-Care (Version 2).}

Lisa A. Chiarello, Robert J. Palisano, Sally Westcott McCoy, and Doreen J. Bartlett, Copyright, 2013, 2017.

FEEDING AND DRINKING -6 items

Feed him/herself finger foods - Score of 5: child feeds self finger foods independently with little spillage and most of the food reaches his/her mouth.

Feed him/herself solid foods using a utensil - Score of 5: child feeds self solid foods using a utensil independently with little spillage and most of the food reaches his/her mouth.

Feed him/herself semi-solid foods (such as applesauce, puddings, mashed potatoes) using a utensil - Score of 5: child feeds self semi-solid foods using a utensil independently with little spillage and most of the food reaches his/her mouth.

Feed him/herself liquid foods (such as soup) using a spoon - Score of 5: child feeds self liquid foods using a spoon independently with little spillage and most of the food reaches his/her mouth.

Drink from a bottle or closed cup - Score of 5: child picks up, holds, and drinks from a bottle/closed cup independently with little spillage.

Drink from an open cup - Score of 5: child picks up, holds, and drinks from an open cup independently with little spillage.

\section{DRESSING - 5 items}

Undress his/her upper body - Score of 5: child takes off shirts that include undoing fasteners, such as buttons, snaps, and zippers.

Dress his/her upper body - Score of 5: child puts on shirts that include doing fasteners, such as buttons, snaps, and zippers.

Undress his/her lower body - Score of 5: child takes off pants/shorts, (skirts if applicable) that include undoing fasteners, such as buttons, snaps, and zippers.

Dress his/her lower body - Score of 5: child puts on pants/shorts, (skirts if applicable) that include doing fasteners, such as buttons, snaps, and zippers.

Put on his/her socks and shoes, including any leg or foot braces - Score of 5: child puts on socks and shoes that include doing shoe fasteners, such as velcro and/or laces and any leg or foot braces. 
GROOMING AND TOILETING - 7 items

Wash and dry his/her hands -Score of 5: child turns water on and off, applies soap and cleans hands, and dries them completely with a towel.

Wash his/her body - Score of 5: child applies soap to and uses washcloth/sponge to clean entire body, including back, arms, legs and face.

Dry off his/her body - Score of 5: child gets and uses towel to dry entire body, including back and hair

Brush his/her hair - Score of 5: child brushes or combs hair, successfully getting tangles out.

Brush his/her teeth - Score of 5: child places toothpaste on the brush, thoroughly brushes teeth, and rinses mouth.

Blow and wipe his/her nose with a tissue - Score of 5: child obtains a tissue, thoroughly blows nose and cleans off face.

Use the potty or toilet - Score of 5: child goes to the toilet, undresses, uses the toilet, wipes self, and redresses.

\section{Response options:}

5: Does the activity independently most of the time

4: Does the activity independently some of the time

3: Does part of the activity independently but needs help for some of the activity

2: Does assist but needs help for all of the activity

1: Does not do the activity. 
TABLE 2. Child and Parent Demographics (McCoy et al., 2018).

\begin{tabular}{|c|c|c|c|c|}
\hline & & \multicolumn{3}{|c|}{ Participants } \\
\hline & & $\begin{array}{c}\text { Baseline } \\
\text { Completed } \\
\text { n=708 }(\%)\end{array}$ & $\begin{array}{l}\text { 12-Month } \\
\text { Completed } \\
\text { n=656 }(\%)\end{array}$ & $\begin{array}{c}\text { 24-Month } \\
\text { Completed } \\
\text { N=424 (\%) }\end{array}$ \\
\hline Child age, years & $\begin{array}{l}\text { Mean (SD) } \\
\text { Minimum-Maximum }\end{array}$ & $\begin{array}{c}6.0(2.7) \\
1.5-12.0\end{array}$ & $\begin{array}{c}7.1(2.7) \\
2.4-13.1\end{array}$ & $\begin{array}{c}8.0(2.7) \\
3.1-14.0\end{array}$ \\
\hline Child Gender & $\begin{array}{l}\text { Male } \\
\text { Female }\end{array}$ & $\begin{array}{l}396(56) \\
312(44)\end{array}$ & $\begin{array}{l}369(56) \\
287(44)\end{array}$ & $\begin{array}{l}242(57) \\
182(43)\end{array}$ \\
\hline $\begin{array}{l}\text { Child Gross Motor } \\
\text { Function Level }\end{array}$ & $\begin{array}{l}\text { I } \\
\text { II } \\
\text { III } \\
\text { IV } \\
\text { V } \\
\end{array}$ & $\begin{array}{c}227(32) \\
161(23) \\
80(11) \\
129(18) \\
111(16) \\
\end{array}$ & $\begin{array}{c}217(33) \\
147(22) \\
73(11) \\
116(18) \\
103(16) \\
\end{array}$ & $\begin{array}{l}135(32) \\
97(23) \\
48(11) \\
75(18) \\
69(16) \\
\end{array}$ \\
\hline $\begin{array}{l}\text { Child Distribution of } \\
\text { Involvement }(\mathrm{n}=707)\end{array}$ & $\begin{array}{l}\text { Monoplegia } \\
\text { Hemiplegia } \\
\text { Diplegia } \\
\text { Triplegia } \\
\text { Quadriplegia }\end{array}$ & $\begin{array}{c}8(1) \\
198(28) \\
184(26) \\
39(6) \\
278(39)\end{array}$ & $\begin{array}{c}8(1) \\
184(28) \\
172(26) \\
38(6) \\
253(39)\end{array}$ & $\begin{array}{c}6(1) \\
114(27) \\
114(27) \\
20(5) \\
170(40)\end{array}$ \\
\hline Child race $(\mathrm{n}=699)$ & $\begin{array}{l}\text { American } \\
\text { Indian/Alaska Native } \\
\text { Asian } \\
\text { Black/African } \\
\text { American } \\
\text { White } \\
\text { Multiple }\end{array}$ & $\begin{array}{c}15(2) \\
40(6) \\
60(8) \\
503(72) \\
81(12)\end{array}$ & $\begin{array}{c}11(2) \\
37(6) \\
56(8) \\
472(73) \\
73(11)\end{array}$ & $\begin{array}{c}3(1) \\
18(4) \\
45(11) \\
310(74) \\
43(10)\end{array}$ \\
\hline $\begin{array}{l}\text { Child ethnicity } \\
(\mathrm{n}=703)\end{array}$ & $\begin{array}{l}\text { Hispanic } \\
\text { Non-Hispanic } \\
\text { Aboriginal } \\
\text { Non-Aboriginal }\end{array}$ & $\begin{array}{c}49(7) \\
654(93) \\
31(4) \\
672(96)\end{array}$ & $\begin{array}{c}43(7) \\
610(93) \\
\\
26(4) \\
627(96) \\
\end{array}$ & $\begin{array}{c}32(8) \\
390(92) \\
9(2) \\
413(98)\end{array}$ \\
\hline $\begin{array}{l}\text { Parent respondent race } \\
(\mathrm{n}=698)\end{array}$ & $\begin{array}{l}\text { American } \\
\text { Indian/Alaska Native } \\
\text { Asian } \\
\text { Black/African } \\
\text { American } \\
\text { White } \\
\text { Multi }\end{array}$ & $\begin{array}{l}15(2) \\
51(7) \\
56(8) \\
550(79) \\
26(4)\end{array}$ & $\begin{array}{c}12(2) \\
45(7) \\
52(8) \\
517(80) \\
22(3)\end{array}$ & $\begin{array}{c}4(1) \\
22(5) \\
42(10) \\
339(81) \\
12(3)\end{array}$ \\
\hline $\begin{array}{l}\text { Parent respondent } \\
\text { ethnicity }(\mathrm{n}=701)\end{array}$ & $\begin{array}{l}\text { Hispanic } \\
\text { Non-Hispanic }\end{array}$ & $\begin{array}{l}32(5) \\
669(95)\end{array}$ & $\begin{array}{c}30(5) \\
621(95)\end{array}$ & $\begin{array}{c}20(5) \\
400(95)\end{array}$ \\
\hline
\end{tabular}




\begin{tabular}{|c|c|c|c|c|}
\hline & $\begin{array}{l}\text { Aboriginal } \\
\text { Non-Aboriginal }\end{array}$ & $\begin{array}{c}20(3) \\
681(97)\end{array}$ & $\begin{array}{c}16(3) \\
635(97)\end{array}$ & $\begin{array}{c}5(1) \\
416(99)\end{array}$ \\
\hline $\begin{array}{l}\text { Parent respondent age, } \\
\text { years }(n=694)\end{array}$ & Mean (SD) & $37.8(7.9)$ & $37.9(8.0)$ & $37.4(7.1)$ \\
\hline $\begin{array}{l}\text { Parent respondent } \\
\text { relationship to child } \\
(\mathrm{n}=704)\end{array}$ & $\begin{array}{l}\text { Mother } \\
\text { Father } \\
\text { Other }\end{array}$ & $\begin{array}{l}628(89) \\
51(7) \\
25(4)\end{array}$ & $\begin{array}{c}578(88) \\
51(8) \\
25(4)\end{array}$ & $\begin{array}{c}382(90) \\
26(6) \\
15(4)\end{array}$ \\
\hline $\begin{array}{l}\text { Parent respondent } \\
\text { education }(\mathrm{n}=700)\end{array}$ & $\begin{array}{l}\text { High School or less } \\
\text { Community College } \\
\text { / Associate's Degree } \\
\text { University }\end{array}$ & $\begin{array}{l}160(23) \\
212(30) \\
328(47)\end{array}$ & $\begin{array}{l}147(23) \\
196(30) \\
307(47)\end{array}$ & $\begin{array}{l}92(22) \\
114(27) \\
214(51)\end{array}$ \\
\hline $\begin{array}{l}\text { Family Income* } \\
(\mathrm{n}=594)\end{array}$ & $\begin{array}{l}\geq \$ 75,000 \\
\$ 60,000-\$ 74,999 \\
\$ 45,000-\$ 59,999 \\
\$ 30,000-\$ 44,999 \\
\leq \$ 30,000\end{array}$ & $\begin{array}{c}306(52) \\
78(13) \\
50(8) \\
58(10) \\
102(17) \\
\end{array}$ & $\begin{array}{c}293(53) \\
72(13) \\
47(8) \\
49(9) \\
92(17) \\
\end{array}$ & $\begin{array}{c}190(52) \\
43(12) \\
34(9) \\
35(10) \\
61(17) \\
\end{array}$ \\
\hline $\begin{array}{l}\text { Family Composition } \\
(n=667)\end{array}$ & $\begin{array}{l}\text { Adults (mean, SD) } \\
\text { Children (mean, SD) }\end{array}$ & $\begin{array}{l}2.1(0.7) \\
2.3(1.1)\end{array}$ & $\begin{array}{l}2.1(0.7) \\
2.3(1.1)\end{array}$ & $\begin{array}{l}2.1(0.7) \\
2.3(1.1)\end{array}$ \\
\hline Country of residence & $\begin{array}{l}\text { Canada } \\
\text { United States }\end{array}$ & $\begin{array}{l}347(49) \\
361(51)\end{array}$ & $\begin{array}{l}330(50) \\
326(50)\end{array}$ & $\begin{array}{l}137(32) \\
287(68)\end{array}$ \\
\hline
\end{tabular}

* Canadian or US dollars

Notes: 'mother' includes mother, adoptive mother, foster mother, or custodial mother; 'father' includes father, adoptive father, or step father; 'other' includes grandparent, nursing supervisor, or aunt. 
TABLE 3. Longitudinal Model Parameters for Each Gross Motor Function Classification System Level.

\begin{tabular}{|c|c|c|c|c|c|}
\hline & Level I & Level II & Level III & Level IV & Level V \\
\hline Fitted model & Model 1 & Model 1 & Model 1 & Model 2 & Model 2 \\
\hline $\begin{array}{l}\text { Number of } \\
\text { Children }\end{array}$ & 227 & 161 & 80 & 129 & 111 \\
\hline $\begin{array}{l}\text { Number of } \\
\text { Observations }\end{array}$ & 874 & 611 & 298 & 487 & 443 \\
\hline $\begin{array}{l}\text { Mean } \\
\text { Observations. } \\
\text { per Child }\end{array}$ & 3.9 & 3.8 & 3.7 & 3.8 & 4 \\
\hline \multicolumn{6}{|c|}{ Fixed Effects (95\% CI) } \\
\hline Limit & $\begin{array}{c}79.6 \\
(76.2,83.1)\end{array}$ & $\begin{array}{c}67.7 \\
(63.3,72.0)\end{array}$ & $\begin{array}{c}62.8 \\
(56.9,68.8)\end{array}$ & $\begin{array}{c}37.9 \\
(35.1,40.8)\end{array}$ & $\begin{array}{c}14.5 \\
(12.0,17.0)\end{array}$ \\
\hline time-90 & $\begin{array}{c}80.3 \\
(65.2,99.0)\end{array}$ & $\begin{array}{c}90.1 \\
(62.3,130.4)\end{array}$ & $\begin{array}{c}106.8 \\
(66.4,171.9)\end{array}$ & $\begin{array}{c}40.2 \\
(29.7,54.4)\end{array}$ & $\begin{array}{c}20.2 \\
(3.7,110.6)\end{array}$ \\
\hline Offset & $\begin{array}{c}-1.4 \\
(-6.6,3.8)\end{array}$ & $\begin{array}{c}-10.1 \\
(-22.7,2.5)\end{array}$ & $\begin{array}{c}-18.1 \\
(-35.5,-0.8)\end{array}$ & & \\
\hline \multicolumn{6}{|c|}{ Random Effects } \\
\hline $\begin{array}{l}\text { Limit } 50 \% \\
\text { Range } \\
\text { time-90 50\% }\end{array}$ & $(70.9,88.4)$ & $(58.7,76.6)$ & $(55.7,69.9)$ & $(28.1,47.8)$ & $(6.0,23.0)$ \\
\hline Range & $(80.3,80.3)$ & $(90.1,90.1)$ & $(106.8,106.8)$ & $(40.0,40.3)$ & $(19.8,20.6)$ \\
\hline $\begin{array}{l}\text { Offset } 50 \% \\
\text { Range }\end{array}$ & $(-1.4,-1.4)$ & $(-10.1,-10.1)$ & $(-18.1,-18.1)$ & & \\
\hline Residual & 6.1 & 5.6 & 4.4 & 5.7 & 6.9 \\
\hline \multicolumn{6}{|c|}{ Estimated Population Values (95\% CI) } \\
\hline 2 years & $\begin{array}{c}41.0 \\
(38.8,42.9)\end{array}$ & $\begin{array}{c}38.9 \\
(35.4,41.7)\end{array}$ & $\begin{array}{c}36.9 \\
(33.6,39.7)\end{array}$ & $\begin{array}{c}28.3 \\
(25.3,31.4)\end{array}$ & $\begin{array}{c}12.5 \\
(7.3,15.7)\end{array}$ \\
\hline 5 years & $\begin{array}{c}65.8 \\
(64.3,67.2)\end{array}$ & $\begin{array}{c}56.2 \\
(54.3,57.8)\end{array}$ & $\begin{array}{c}50.8 \\
(48.7,52.7)\end{array}$ & $\begin{array}{c}36.6 \\
(34.5,38.7)\end{array}$ & $\begin{array}{c}14.1 \\
(11.6,16.3)\end{array}$ \\
\hline 12 years & $\begin{array}{c}78.3 \\
(76.0,80.4)\end{array}$ & $\begin{array}{c}66.1 \\
(63.5,68.5)\end{array}$ & $\begin{array}{c}60.5 \\
(57.3,63.3)\end{array}$ & $\begin{array}{c}37.9 \\
(35.6,40.3)\end{array}$ & $\begin{array}{c}14.5 \\
(12.4,16.5)\end{array}$ \\
\hline
\end{tabular}


TABLE 4. Mean Change in Reference Percentile for Performance in Self-Care for 12 Month Period by Gross Motor Function Classification System Level.

\begin{tabular}{lccccc}
\hline & Level I & Level II & Level III & Level IV & Level V \\
\hline Number of Participants & 217 & 136 & 68 & 111 & 101 \\
Mean Change & 8.5 & 5.5 & 3.1 & 4.5 & 0.7 \\
Standard Deviation & 19.8 & 15.3 & 20.4 & 14.1 & 14.2 \\
25-75\% Interval & $-3,+20$ & $-3,+14$ & $-8,+15$ & $-2,+11$ & $-3,+5$ \\
10-90\% Interval & $-13,+37$ & $-12,+26$ & $-17,+25$ & $-13,+24$ & $-17,+18$ \\
\hline
\end{tabular}




\section{GMFCS Lqkygitital \& Occupational therapy In Pediatrics GMFCS Level II Page 30 of 33}

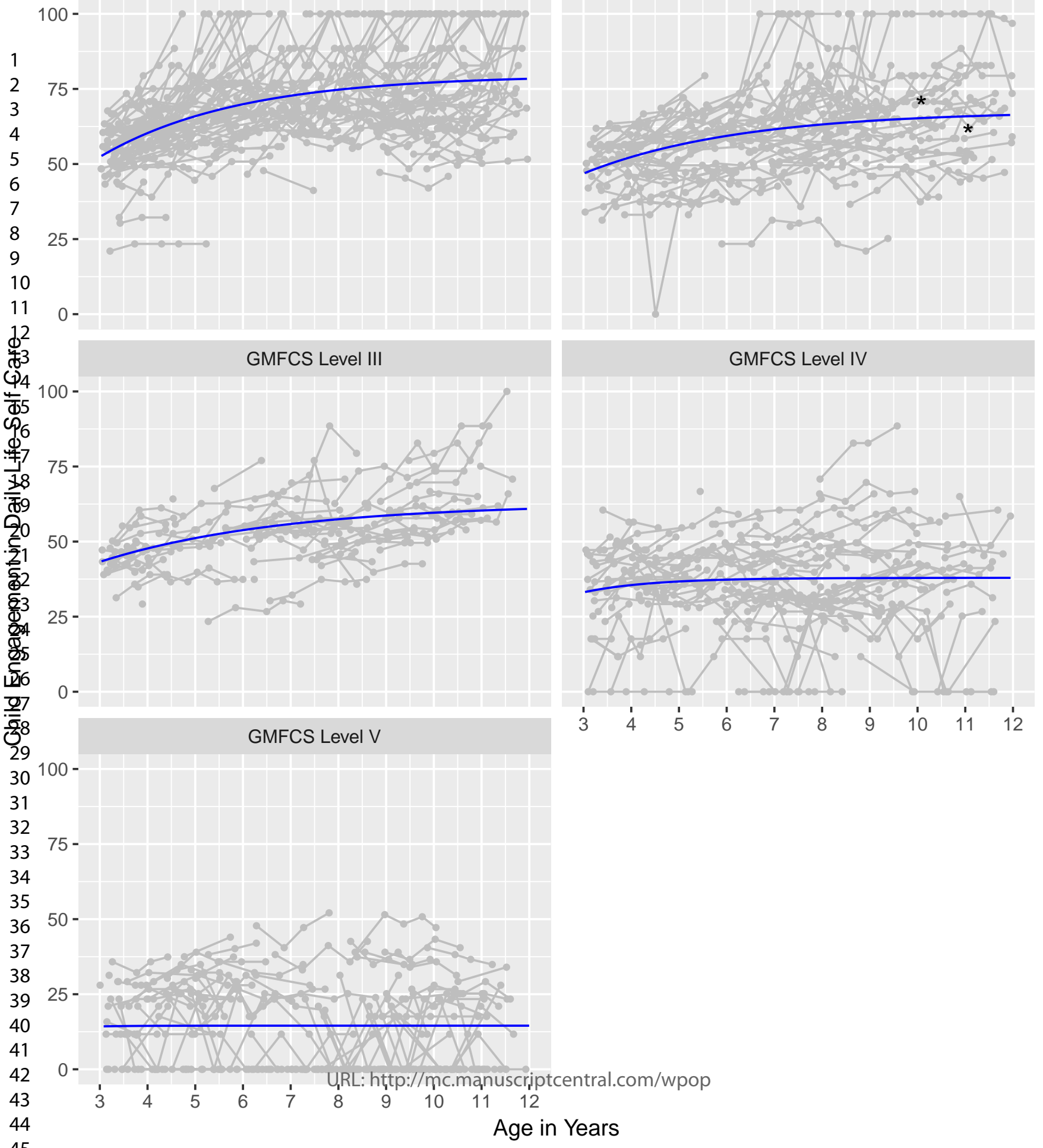


GMFCS Level III

100 -

\section{GMFCS LevelV}

25 -

0 -
GMFCS Level IV
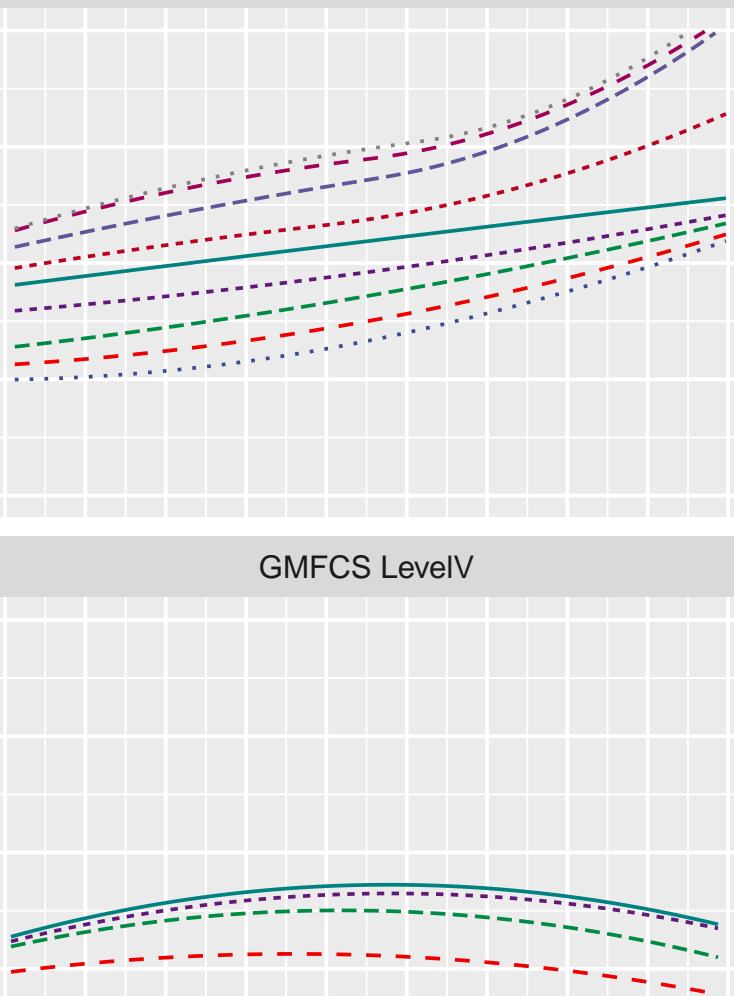

$\begin{array}{llllllllll}1 & 1 & 1 & 1 & 1 & 1 & 1 & 1 & 1 & 1\end{array}$

\section{Age in Years}

URL: http://mc.manuscriptcentral.com/wpop

Centile $\cdots 3--5--\cdot 10 \cdots 25-50 \cdots 95--\cdot 90--95 \cdots 97$ 
FIGURE 1. Longitudinal Trajectories for Performance in Self-Care of Children with Cerebral Palsy. Asterisks for level II pertain to case scenario.

FIGURE 2. Reference Percentiles for Performance in Self-Care of Children with Cerebral Palsy. Asterisks for level II pertain to case scenario. 


\section{APPENDIX - STATISTICAL SUPPLEMENT}

\section{Model 1 (GMFCS Levels I, II \& III)}

$$
y=\operatorname{Limit}\left(1-e^{-e^{\lambda}(\text { age }-\delta)}\right)
$$

This is an asymptotic model with three parameters: the Limit parameter represents the average maximum score, the rate parameter, $\lambda$ is re-parameterized to Age-90, using the formula below and $\delta$, an offset parameter to improve model fit.

\section{Model 2 (GMFCS Levels IV \& V)}

$$
y=\operatorname{Limit}\left(1-e^{-e^{\lambda} a g e}\right)
$$

As with Model 1, this model directly estimates the Limit parameter and the rate parameter, $\lambda$ is re-parameterized to Age-90, using the formula below.

\section{Re-parameterization of the rate parameter, $\lambda$}

time $90=\frac{-\log (1-0.9)}{e^{\lambda}}$ is the length of time required for $90 \%$ of the Limit to be achieved.

$50 \%$ Ranges

$50 \%$ Ranges represent the expected range of the parameter for the central $50 \%$ of the population and were calculated as fixed effect $\pm \mathrm{z}_{0.25} \mathrm{x}$ random effect

\section{Population Predicted Means}

To facilitate comparisons across levels the population-level outcome values at ages 2, 5, and 12 years were predicted for each model. Confidence intervals were calculated by drawing a sample of 1000 fixed effects estimates from the fitted parameters and their covariance matrix using the multivariate normal distribution. 